Journal of Agricultural Sciences
(Tarim Bilimleri Dergisi)

\title{
Determining the Effects of Climate Change and Market Prices on Farm's Structure by Using an Agent Based Model
}

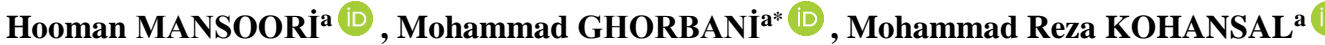 \\ ${ }^{a}$ Department of Agricultural Economics, Agricultural College, Ferdowsi University of Mashhad, Mashhad, IRAN \\ ARTICLE INFO \\ Research Article \\ Corresponding Author: Mohammad GHORBANI, E-mail: ghorbani@um.ac.ir \\ Received: 11 December 2018 / Revised: 21 December 2019 / Accepted: 07 February 2020 / Online: 31 May 2021
}

\section{ABSTRACT}

In this study, an agent-based model was used to simulate structure change of farms during 20 years period of climate and market price changes in the rural area of Eslamshahr City in Iran. Decision rules that used in the model are based on the information that collected by direct interviews with farmers. So the model includes rules that define the relationship between agents and their environment. Results clearly showed that farmers' behavior patterns and the cover of agricultural land in the region affected by environmental and market factors changes. Comparison of the results of model implementation for various scenarios has shown that the highest yield and income loss has occurred in scenarios where there was a $10 \%$ reduction in access to water. Also, there is a less decrease in the crops land size in groups which includes small and medium farmers.

Keywords: Agent based, Climate, Farm Structure, Land use, Iran

(C) Ankara University, Faculty of Agriculture

\section{Introduction}

The social, economic and spatial dynamics of rural regions are often affected by the processes and dynamics of the agricultural farm structure changes. These dynamics are complex processes caused by the interaction between natural and social systems at different scales. The role that a farm takes within this complex process depends not only on the farm's characteristics, the characteristics of the farmer or farm manager but also on local competition, as well as the economic, institutional and environmental conditions. For an adequate understanding of the underlying processes, it is important to capture not only the interactions amongst and between farms and their environment but also the farms' behavior, and their decision processes (Appel \& Balmann 2018).

The ongoing internal and external pressure on farmers has resulted in the fluctuation of gross margins, income, and a continuous change in the number of farmers in the region. Understanding these significant trends and their impact on the farm structure requires a deeper knowledge of the mechanisms involved and the impacts of different policy measures (Beckers et al. 2018). The core theme of agriculture structural change science is to understand the dynamics of the farmer's decision-making rules according to these trends (Schindler 2009). As mentioned above, the driving forces can be categorized as endogenous and exogenous processes of a region. Endogenous processes are socio-economic and biophysical conditions of farms in a specific region including farmer's experience, preferences, economic condition, and land fertility. Exogenous processes are those occurring at global, national and regional scales, varying from changes in the market prices to climate change and policy frameworks (Valbuena et al. 2010).

Agriculture is one of the most climate-sensitive sectors and directly affected by changes in climate conditions. Farmers may implement climate change adaptation measures to reduce or avoid adverse developments and take advantage of emerging opportunities. Others may forbear to adapt which results in a lack of timely adaptation. On the other hand, the volatility and price imbalance of agricultural products and inputs as an exogenous factor influences farmer's income and expenditure situation and, consequently, the welfare of their lives. The change in farmers' welfare status will shape the decision-making process and the selection of activity options in the upcoming period. Farmers' adaptation decisions -such as other human behavior- is influenced by the individual characteristics and economic and social conditions of the farmer (Mitter et al. 2019). Agriculture in Iran is also affected by market prices and climatic conditions, which can lead to changes in farmer preferences and behavior, and change in agricultural cover and economic outcomes in the region. Iran is one of the world's water-scarce regions and is extremely vulnerable to the impacts of climate change due to its high dependency on climate-sensitive agriculture (Karimi et al. 2017). A new approach to analyze and simulate farm structural changes according to exogenous and endogenous factors is the use of agent-based simulation models. Behavioural or 'process-based' models such as agent-based models (ABMs) have received 
increasing attention because they allow the simulation of emergent social and economic conditions from underlying external factors such as climate changes and market prices fluctuations and internal factors like behavioral processes of farmer's decision making and land use changes (Seo et al. 2018). Hailegiorgis et al. (2018), used an agent-based model to find the impact of climate change on the adaptive capacity of rural communities in Ethiopia and showed that climate effects caused farmers to migrate from the region. Lamperti et al. (2017) introduced an agent-based model to assess and monitor the Coupled Climate and Economic Dynamics. Wossen et al. (2017) provided an ex-ante assessment of the impacts of climate and price variability on household income and food security in Ethiopia and Ghana.

The ABM model in this research includes a socio-ecological system representing the farm region of "Eslamashahr" in Iran that is informed by empirical data from a social survey about the behavior and heterogeneity of farmers. This area covers 4 rural main districts and 49 villages. The dominate cultivation crops are wheat, barley, corn, and alfalfa. According to Iran's third national report to UNFCC (The United Nations Framework Convention on Climate Change, 2017), the projections of mean temperature based on scenarios for Iran show that the mean temperature will increase in the whole country in future decades compared to the baseline period. So, the temperature is estimated to increase up to 1 degree in some parts of the country that the current study was conducted. Also, precipitation changes in the area will be up to $-4.4 \%$. Meanwhile, according to the data provided by the statistics of the Ministry of Agriculture and Statistics of Iran in different years, farmers in this region like other parts of the country face annual changes in prices of products and production costs, as in recent years, the average prices of agricultural products has grown $9.66 \%$, and the average annual cost of production has grown by $13.08 \%$. Therefore, the purpose of this study is to understand how the interaction between agents or farmers in agricultural land with climate change in the region and market fluctuations, and to simulate and measure the economic outcomes of this interaction for 20 years. Whilst ABM is increasingly applied to assess farm structural changes in several regions and countries but to our knowledge, no similar agentbased studies have been so far conducted in Iran.

\section{Material and Methods}

This research adopted an agent-based model as a suitable approach to quantify the agricultural systems, their structural change, and endogenous adjustment to climate changes and price volatilities in "Eslamshahr" as an example of a traditional agricultural landscape during a period of 20 years from 2016 to 2036. The model was constructed using the NetLogo software. The framework of this model and the type of variables for entry into the simulation model Were determined after the review of previous similar studies (Lobanco \& Esposti 2010; Bert et al. 2011; Lamperti et al. 2017) and according to the conditions of the farmers in the region. Farmers' economic and social heterogeneity and their differences in reaction thresholds to external factors lead to their different outcomes in a given period. Here, quantitative models based on aggregated data can't meet the research needs but in agent-based framework, the model is implemented for every individual agent and ultimately the overall agricultural region profile can be simulated. Information was collected from interviews with farmers and agricultural administrators. The environment, which influences farmer's decisions, is defined based on economic and climatic parameters. The economic parameters include product prices and costs of production such as fertilizers, pesticides, labor, and land costs (i.e. rental price). The climatic parameters are represented by the effects of temperature and rainfall on yields. Considering the diversity of farm sizes in the county, a stratified sampling method was selected with proportional allocation. The sample size was 195 (out of 585 households) and the variables used in the research model are defined in Table 1:

Table 1- Variables used in agent based model

\begin{tabular}{ll}
\hline Variable & Description \\
\hline$G I_{j, t}=P_{j, t} * Y_{j, t}$ & Gross income of each crop per hectare (Tomans) \\
$C L_{J}$ & Land size of crop J (hectares) \\
$T C L_{t}=\sum C L_{j, t}$ & Total farm land size (hectares) \\
$T G I_{t}=\sum\left(G I_{j, t} * C L_{j, t}\right)$ & Total farm gross income (Tomans) \\
$T E X P_{t}=\sum\left(E X P_{j, t} * C L_{j, t}\right)$ & Total farm costs (Tomans) \\
$T N I_{t}=T G I_{t}-T E X P_{t}$ & Total farm net income (Tomans) \\
$N I_{t}=T N I_{t} / T C L_{t}$ & Net income per hectare (Tomans) \\
$L A B O R_{t}=\sum_{j}\left(L A B O R_{j, t} * C L_{j, t}\right)$ & Total farm labor (man \\
$A L_{t}$ & Aspiration level or expected income per hectare (Tomans) \\
$O C=R P_{t}+I R_{t}$ & Opportunity cost of a period of use of each hectare (Tomans) \\
$R P_{t}$ & Average value of rent per hectare of farm land in the region (Tomans) \\
$I R_{t}=0.15 *\left(R P_{t}+E X P_{t}\right)$ & Interest amount (interest rate=0.15), (Tomans) \\
$W C_{t}=T N I_{t}-S I N C_{t}+T R I_{t}-T R E_{t}+W C_{t-1}$ & Working capital (Tomans) \\
$N L=[W C / R P]$ & Maximum land that farmer can lease in the next period potentially \\
$S I N C_{t}$ & Farmer's Household Livestock Minimum Cost (Tomans) \\
$T R I_{t}=R P_{t} \cdot R C L_{t}$ & Total revenue from land rent out (Tomans) \\
$T R E_{t}=R P_{t} \cdot L C L_{t}$ & Total cost of leasing farm land (Tomans) \\
$R C L_{t}$ & The amount of land rented out (hectares) \\
$L C L_{t}$ & The amount of land leased (hectares) \\
\hline
\end{tabular}


The adaptive decisions of the farmers depend on several rules. These rules were derived from interview results. For example, 1: farmers compute their opportunity cost and compare that with farming income; 2: farmers remember their past income and consider changing land use (crop pattern), If their income gap from the expected income level (say aspiration level) increases; 3: if farming income gap from aspiration level in successive consecutive periods increases (in this research, three periods), then they supply their land for rent or will abandon farming in it. 4) Farmers with enough working capital will demand land for rent potentially. The implementation process of the simulation model and adaptive decisions are presented in the decision tree (fig.), which provides a framework for the empirical application of the ABM.

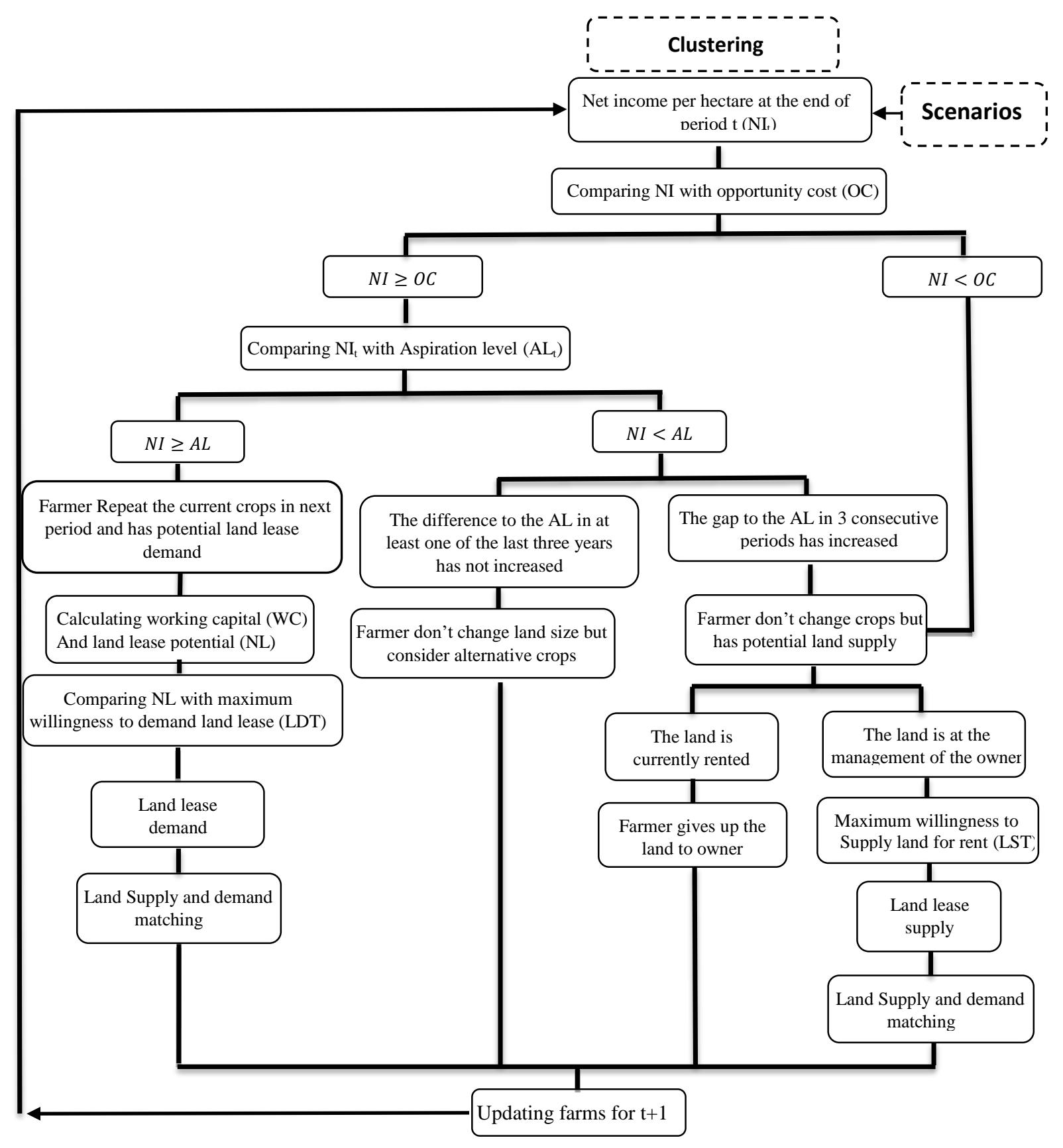

Figure- Decision tree of Agent based model

\subsection{Scenario preparation}

In this research, it is assumed that the product yield per hectare for each farm, changes due to climate parameters over a given period. So employing the FAO 56 approach, the response of yields of crops in the study region was quantified by the yield-water relations for each farmer (Allen et al. 1998). Thereby actual changes in the yield of various crops can be defined under different climate scenarios over 20 years period (Table 2). All data used for variables in this relation derived from agricultural and Economic vulnerability subdivision of Iran's third national communication to the United Nations Framework Convention on Climate Change. 
Table 2- Climate change pre-scenarios

\begin{tabular}{|c|c|c|c|c|c|c|}
\hline \multirow{2}{*}{\multicolumn{7}{|c|}{$\frac{\text { - Percentage of change in annual rainfall: }-4.4 \%}{- \text { Percentage of change in annual temperature: }+1 \%}$}} \\
\hline & & & & & & \\
\hline & & \multirow{2}{*}{ Condition } & \multicolumn{4}{|c|}{ Annual Change of yields $(\alpha)$} \\
\hline & & & wheat & barley & maize & alfalfa \\
\hline A1 & Fixing access to water as much as the base year & & $-0.3 \%$ & $-0.27 \%$ & $-3.16 \%$ & $-0.17 \%$ \\
\hline A2 & Reducing $10 \%$ of access to water & & $-0.79 \%$ & $-0.8 \%$ & $-0.88 \%$ & $-0.64 \%$ \\
\hline
\end{tabular}

Notes: -In scenario A1 it is assumed that, despite the decrease in rainfall over a period of time, using improved technology, through proper irrigation, the available water is fixed at the base year and main reason of yield decrease is changing climate and crop evapotranspiration, -In scenario A2 it is assumed that the total amount of available water for agriculture will decrease by $10 \%$ at the end of the simulation period

In this research, two pre-scenarios are defined about predicted changes in products prices and production cost.

Table 3- Price changes pre-scenarios

\begin{tabular}{llcc}
\hline & Pre-scenarios & $\begin{array}{c}\text { Annual growth rate of } \\
\text { product price }\end{array}$ & $\begin{array}{c}\text { Annual growth rate of } \\
\text { production costs }\end{array}$ \\
\hline B1 & Growth rate of production costs $\leq$ growth rate of product prices & $+9.66 \%$ & $+13.86 \%$ \\
B2 & Growth rate of production costs = growth rate of product prices & $+13.86 \%$ & $+13.86 \%$ \\
\hline
\end{tabular}

Notes: - In scenario B1, it is assumed that production costs and prices of the products are the same as the past 15 years (annual change of products prices= $+9.66 \%$ and annual change of production costs $=+13.86 \%$ ), -In scenario B2, production costs and product prices grow by as much as 13.86 percent.

Based on the above pre-scenarios, the following mixed scenarios are presented:

A1B1: fixed water access as much as the base year + continued trend over the last 15 years in rising product prices and production costs

A1B2: fixed water access as much as the base year + similar changes in product prices and production costs

A2B1: $10 \%$ reduction in water access + continued trend over the last 15 years in rising product prices and production costs A2B2: $10 \%$ reduction in water access + similar changes in product prices and production costs

\subsection{Economic calculations}

This submodel calculates the economic results for a farmer during one full production cycle. After preparing scenarios, by using variables such as total production costs (TEXP), product prices $(\mathrm{Pj})$, yield per hectare (Yj), total gross income (TGI), gross income per hectare (GI), and net income in each hectare (NI) would be calculated at the end of each period $t$.

Variables that directly would be affected by scenarios include:

$Y_{j, t}=Y_{j, 0} *(1+\alpha)^{t}:$ Yield in a hectare of product $\mathrm{j}$ in year $\mathrm{t}$

$P_{j, t}=P_{j, 0} *(1+\beta)^{t}:$ Market price of product $\mathrm{j}$ in year $\mathrm{t}$

$E X P_{j, t}=E X P_{j, 0} *(1+\beta)^{t}:$ Production cost in a hectare of product $\mathrm{j}$ in year $\mathrm{t}$

A part of the results of the submodel is the financial balance for a farmer and his/her household at the end of a cycle. The balance is expressed as the working capital accumulated by an agent at the end of the cycle (WC). Briefly, the accumulation of working capital is the result of the balance between available capitals from previous cycles, received total income, and incurred total expenses during a production cycle. After calculating the net income per hectare (NI), the farmer calculates the opportunity cost of the agricultural activity (OC) and compares it with the NI. If the net income of each hectare is greater than or equal to the cost of opportunity, then the farmer will compare the net incomes per hectare (NI) with the expected value or Aspiration level (ALt) (Bert et al. 2011). The aspiration level would be calculated by average income per hectares of successful farmers in the region. It is assumed that farmers with the highest technical efficiency are successful farmers. For this purpose, the technical efficiency coefficient of all farms was calculated by the DEA ${ }^{1}$ method and the average of NI for farmers in each cluster with an efficiency coefficient above 0.8 determined as aspiration level in that cluster. Now, if the net income is less than the aspiration level, then the process of changing the gap or the difference with this threshold will be the benchmark for the decision. If this gap increases for three consecutive years, the farmer will have a potential supply of land.

$$
\left(N I_{t} / A L_{t}\right)>\left(N I_{t-1} / A L_{t-1}\right)>\left(N I_{t-2} / A L_{t-2}\right)
$$

${ }^{1}$ Data envelopment analysis 
If the net income per hectare is less than the expected value, but the difference does not increase for all three consecutive years, the farmer will only seek to replace the crops according to crop preferences. So he will choose crops for the next year from a discrete set of available options. For this purpose, crop preferences were determined by performing an interview with farmers and utility values obtained for each crop according to their statements. If the land is rented, it will be transferred to the owner and if the land is a property, then the land offered for rent is equivalent to the maximum willingness to rent out (LST), that previously obtained by interviewing each farmer. If $\mathrm{NI} \geq \mathrm{AL}$, the current period cropping pattern will be repeated in the next period and the farmer will have a potential land lease demand. For farmers who have a potential land lease demand, at first the working capital (WC) will be calculated and then the maximum land that farmers can lease (NL) will be determined (Bert et al. 2011). Comparing (NL) with the maximum willingness to lease land (LDT) determines the actual demand for land lease. If NL $\geq$ LDT then actual demand is equal to LDT and if NL $<$ LDT then it is equal to NL.

\section{Results and Discussion}

Before running the simulation model, farmers were divided into three classes to obtain different classes proportional to the size and scale of production, using K-Means clustering method. In this method, every data point is allocated to each of the clusters through reducing the in-cluster sum of squares. In other words, the K-means algorithm identifies k number of centroids, and then allocates every data point to the nearest cluster, while keeping the centroids as small as possible. So, Cluster 1 with 105 farmers, cluster 2 with 378 farmers and cluster 3 with 378 farmers were identified.

\subsection{Simulation model results}

The results show that in A1B1 scenario the total cropping land size in cluster 2 and cluster 1 have the highest decrease at the end of the simulation period. Large-scale farmers are more flexible while reducing economic benefits due to increased production costs (in this scenario, the rate of increase in production costs is higher than the rate of increase in prices of products), but smaller farmers with lower income earnings respond quicker. According to the model decision tree, which compares net income per hectare with the opportunity cost and also net income per hectare with expected income (Aspiration level) over consecutive periods, a larger percentage of small farmers Due to the lack of desirability, reduced their cultivated land or stop cultivating to use the released capital in other businesses. Comparison of yield changes per hectare of the products indicated that the highest yield loss was due to the wheat product, which is reduced by $5.8 \%$, and in all three clusters this reduction value is the same. The yield of barley and alfalfa products in cluster 3, which includes large-scale farmers, has declined less. It seems that farmers have been able to compensate for the decline in yields due to climate change, given access to more machinery and equipment and the use of agronomic methods.

Table 4- Simulation results for A1B1 scenario

\begin{tabular}{|c|c|c|c|c|c|c|c|c|c|}
\hline & \multicolumn{3}{|c|}{ Cluster 1} & \multicolumn{3}{|c|}{ Cluster 2} & \multicolumn{3}{|c|}{ Cluster 3} \\
\hline & $A 1 B 1$ & $A O B O$ & $\begin{array}{l}\text { Change } \\
\text { percent }\end{array}$ & $A 1 B 1$ & $A O B O$ & $\begin{array}{l}\text { Change } \\
\text { percent }\end{array}$ & $A 1 B 1$ & $A O B O$ & $\begin{array}{l}\text { Change } \\
\text { percent }\end{array}$ \\
\hline Total cropping land size (hectares) & 304.5 & 327 & -6.8 & 1179 & 1275 & -7.5 & 4884 & 4989 & -2.1 \\
\hline Yield in hectare of wheat $(\mathrm{kg})$ & 3651 & 3877 & -5.8 & 4025 & 4275 & -5.8 & 4915 & 5220 & -5.8 \\
\hline Yield in hectare of barley $(\mathrm{kg})$ & 3631 & 3833 & -5.2 & 3719 & 3926 & -5.2 & 4823 & 5071 & -4.8 \\
\hline Yield in hectare of maize $(\mathrm{kg})$ & 40363 & 40800 & -1.07 & 42892 & 44288 & -3.1 & 50355 & 52000 & -3.1 \\
\hline Yield in hectare of alfalfa $(\mathrm{kg})$ & 13531 & 14000 & -3.35 & 13628 & 14100 & -3.3 & 14134 & 14579 & -3.05 \\
\hline Income/cost index & 1.54 & 2.72 & -43.3 & 1.58 & 2.98 & -45.3 & 2 & 3.8 & -47.3 \\
\hline $\begin{array}{l}\text { Average labor work in each farm } \\
\text { (labors*Days) }\end{array}$ & 136 & 151 & -9.9 & 140 & 152 & -7.8 & 2058 & 2076 & -0.86 \\
\hline
\end{tabular}

To compare the economic indicators of farmers in three clusters, the ratio of total income to total cost is used. As can be seen, the value of this index in cluster 3 is higher than the other two clusters. The lowest employment reduction rate is for cluster 3 farmers, which was only $0.86 \%$ lower than the beginning of the period.

In A1B2 scenario, total cropping land size in the cluster 2 has the highest decrease. The highest yield in hectare loss is due to wheat production, which is reduced by $5.8 \%$, and in all three clusters this reduction is similar. The value of the income/expense ratio in cluster 2 and 3 is higher than cluster 1.

In the A2B1 scenario, it is assumed that the total water consumption of crops will decrease by $10 \%$. As a result, the yield loss is not only due to an increase in evapotranspiration but also a reduction in water availability. On the other hand, in this scenario, it is assumed that the changes in annual product prices and production costs are the same as in the last 15 years, with the price of products rising by $9.66 \%$ annually and production costs by $13.068 \%$. Comparison of yield changes per hectare of the products 
showed that the highest yield loss was related to alfalfa. The value of the ratio of income to expense at the end of the simulation period in cluster 2 and 3 is higher than cluster 1 .

Table 5- Simulation results for A1B2 scenario

\begin{tabular}{|c|c|c|c|c|c|c|c|c|c|}
\hline \multirow{2}{*}{ Variable } & \multicolumn{3}{|c|}{ Cluster 1} & \multicolumn{3}{|c|}{ Cluster 2} & \multicolumn{3}{|c|}{ Cluster 3} \\
\hline & $A 1 B 1$ & $A O B O$ & $\begin{array}{l}\text { Change } \\
\text { percent }\end{array}$ & $A 1 B 1$ & $A O B O$ & $\begin{array}{l}\text { Change } \\
\text { percent }\end{array}$ & $A 1 B 1$ & $A O B O$ & $\begin{array}{l}\text { Change } \\
\text { percent }\end{array}$ \\
\hline Total cropping land size (hectares) & 321 & 327 & -1.8 & 1221 & 1275 & -4.2 & 4878 & 4989 & -2.2 \\
\hline Yield in hectare of wheat $(\mathrm{kg})$ & 3651 & 3877 & -5.8 & 4025 & 4275 & -5.8 & 4915 & 5220 & -5.8 \\
\hline Yield in hectare of barley $(\mathrm{kg})$ & 3631 & 3833 & -5.2 & 3719 & 3926 & -5.2 & 4823 & 5071 & -4.8 \\
\hline Yield in hectare of maize (kg) & 40363 & 40800 & -1.07 & 42892 & 44288 & -3.1 & 50355 & 52000 & -3.1 \\
\hline Yield in hectare of alfalfa $(\mathrm{kg})$ & 13532 & 14000 & -3.3 & 13628 & 14100 & -3.3 & 14134 & 14579 & -3.05 \\
\hline Income/cost index & 2.81 & 2.72 & 3.3 & 2.9 & 2.98 & -2.6 & 3.7 & 3.8 & -2.6 \\
\hline $\begin{array}{l}\text { Average labor work in each farm } \\
\text { (labors*Days) }\end{array}$ & 144 & 151 & -4.6 & 145 & 152 & -4.6 & 2058 & 2076 & -0.86 \\
\hline
\end{tabular}

Table 6- Simulation results for A2B1 scenario

\begin{tabular}{|c|c|c|c|c|c|c|c|c|c|}
\hline \multirow[b]{2}{*}{ Variable } & \multicolumn{3}{|c|}{ Cluster 1} & \multicolumn{3}{|c|}{ Cluster 2} & \multicolumn{3}{|c|}{ Cluster 3} \\
\hline & A1B1 & $\mathrm{A} 0 \mathrm{~B} 0$ & $\begin{array}{l}\text { Change } \\
\text { percent }\end{array}$ & A1B1 & A0B0 & $\begin{array}{l}\text { Change } \\
\text { percent }\end{array}$ & A1B1 & $\mathrm{A} 0 \mathrm{~B} 0$ & $\begin{array}{l}\text { Change } \\
\text { percent }\end{array}$ \\
\hline Total cropping land size (hectares) & 259 & 327 & -20.7 & 1223 & 1275 & -4.07 & 4774 & 4989 & -4.3 \\
\hline Yield in hectare of wheat $(\mathrm{kg})$ & 3309 & 3877 & -14.6 & 3647 & 4275 & -14.6 & 4454 & 5220 & -14.6 \\
\hline Yield in hectare of barley (kg) & 3264 & 3833 & -14.8 & 3343 & 3926 & -14.8 & 4336 & 5071 & -14.4 \\
\hline Yield in hectare of maize $(\mathrm{kg})$ & 34924 & 40800 & -14.4 & 37111 & 44288 & -16.2 & 43569 & 52000 & -16.2 \\
\hline Yield in hectare of alfalfa $(\mathrm{kg})$ & 12313 & 14000 & -12.05 & 12400 & 14100 & -12.05 & 12861 & 14579 & -11.7 \\
\hline Income/cost index & 1.37 & 2.72 & -49.6 & 1.39 & 2.98 & -53.42 & 1.77 & 3.8 & -53.42 \\
\hline $\begin{array}{l}\text { Average labor work in each farm } \\
\text { (labors*Days) }\end{array}$ & 117 & 151 & -22.5 & 144 & 152 & -5.2 & 2016 & 2076 & -2.89 \\
\hline
\end{tabular}

In the A2B2 scenario, as in the previous, a 10\% reduction in water availability will exacerbate this decline in yields. Also, the annual price changes of products and production costs are the same and grow as much as $13.68 \%$ annually. Results showed that total cropping land size of the area in cluster 2 and cluster 1 have the greatest decrease.

Table 7- Simulation results for A2B2 scenario

\begin{tabular}{lrrrrrrrrr}
\hline \multirow{1}{*}{ Variable } & \multicolumn{3}{c}{ Cluster 1 } & \multicolumn{3}{c}{ Cluster 2 } & \multicolumn{2}{c}{ Cluster 3 } \\
\cline { 2 - 9 } & AlB1 & AOBO & $\begin{array}{l}\text { Change } \\
\text { percent }\end{array}$ & AlB1 & AOBO & $\begin{array}{l}\text { Change } \\
\text { percent }\end{array}$ & AlB1 & AOBO $\begin{array}{l}\text { Change } \\
\text { percent }\end{array}$ \\
\hline Total cropping land size (hectares) & 294 & 327 & -10.09 & 1214 & 1275 & -4.7 & 4872 & 4989 & -2.3 \\
Yield in hectare of wheat (kg) & 2308 & 3877 & -14.6 & 3647 & 4275 & -14.6 & 4454 & 5220 & -14.6 \\
Yield in hectare of barley (kg) & 3264 & 3833 & -14.8 & 3343 & 3926 & -14.8 & 4336 & 5071 & -14.4 \\
Yield in hectare of maize (kg) & 34924 & 40800 & -14.4 & 37111 & 44288 & -16.2 & 43569 & 52000 & -16.2 \\
Yield in hectare of alfalfa (kg) & 12312 & 14000 & -12.05 & 12400 & 14100 & -12.05 & 12861 & 14579 & -11.7 \\
Income/cost index & 2.51 & 2.72 & -7.72 & 2.58 & 2.98 & -13.4 & 3.29 & 3.8 & -13.4 \\
$\begin{array}{l}\text { Average labor work in each farm } \\
\text { labors*Days) }\end{array}$ & 132 & 151 & -12.5 & 143 & 152 & -5.9 & 2055 & 2076 & -1.01 \\
\hline
\end{tabular}

\section{Conclusions}

In this research, the results of the implementation of the agent-based simulation model to study farm structural changes in the rural area of "Eslamshahr" for 20 years are presented in detail. The simulation results clearly showed that farmers' behavior patterns and the agricultural land cover affected by environmental and market factors variation. This is consistent with numerous studies related to the underlying agent-based simulation (Lobianco \& Esposti 2010; Bert et al. 2011; Acosta et al. 2014; Lamperti et al. 2017; Wossen et al. 2017, Seo et al. 2018). Results also suggested that the preferences and subjective priorities of each farmer in determining the cropping pattern and selection of products have a significant effect on the final agricultural cover in the region, which is similar to the results of Valbuena et al. (2010). Results indicated that at the end of the simulation period, due to climate change, water scarcity and the change of the prices of products and production costs, the number of active agricultural farms in the cluster 1, which includes small-scale farmers, will be further reduced. Also, the employment in the agricultural sector across all scenarios and the total cropping land size in the number of scenarios will decrease. Such a decrease intensifies under the scenario of a 10 percent reduction in water access and the continuation of the past trend in the annual change in prices and production costs (A2B1). In scenario A2B1 and A2B2, where the $10 \%$ reduction in access to water occurs during the simulation period, there is the highest yield loss, for example, wheat yields fall by more than $14 \%$ in cluster 3 . This has resulted 
in numerous consequences such as declining production and employment, changing the dominant agricultural profile in the region, and increasing the likelihood of land use change. It is essential to create adequate incentives for farmers by the government to compensate for the adverse effects of possible scenarios and encouraging the development of modern agricultural practices to reduce the functional effects of climate change and the lack of access to water.

Encouraging the development of products that demonstrate greater flexibility and adaptation to climate change can be one of the suggested strategies. The promotion and training of modern agricultural practices and the provision of mechanization needed by farmers in the region will help to improve the performance of agricultural farms. The highest drop in employment was observed in small and medium-size agricultural units. There is also the highest income/cost ratio in large agricultural units. Appropriate policies and support orientation towards small and medium-size farms are necessary to increase competitiveness and sustainability in situations where production performance is reduced in the simulation horizon. In a situation where in the coming years, small scale farms will have a more economic vulnerability to climate change and market fluctuations, encouraging the creation and development of production cooperatives in the region with the participation of small-scale farms can lead to increased productivity and reduced costs.

\section{References}

Acosta L, Rounsevell M, Bakker M, Van Doorn A, Montserrat G \& Delgado M (2014). An agent-based assessment of land use and ecosystem changes in the traditional agricultural landscape of Portugal. Journal of Intelligent Information Management 6(2):5580 https://doi.org/10.4236/iim.2014.62008

Allen R, Pereira L S, Raes D \& Smith M (1998). Crop evapotranspiration, Guidelines for computing crop water requirements. FAO Irrigation and drainage, paper 56, Food and Agriculture Organization of the United Nations

Appel F \& Balmann A (2018). Human behavior versus optimizing agents and the resilience of farms-Insights from agent-based participatory experiments with Farm AgriPoliS. Ecplogical Complexity 40(100731) https://doi.org/10.1016/j.ecocom.2018.08.005

Beckers V, Beckers J, Vanmaecke M \& Van Hecke, E (2018). Modelling farm growth and its impact on Agricultural land use: A country scale application of an agent-based model. Journal of Land 7(3): 109 https://doi.org/10.3390/land7030109

Bert F, Podesta P, Rovere S \& Menendez A (2011). An agent-based model to simulate structural and land-use changes in agricultural systems of the Argentine pampas. Journal of Ecological Modelling 22(19): 3486-3499 https://doi.org/10.1016/j.ecolmodel.2011.08.007

Hailegiorgis A, Crooks A \& Cioffi-Revilla C (2018) An agent-based model of rural households' adaptation to climate change. Journal of Artificial Societies and Social Simulation 21(4): 4 https://doi.org/10.18564/jasss.3812

UNFCC (2017). Iran's third national report, National climate change office at the department of environment on behalf of the government of the Islamic Republic of Iran

Karimi V, Karami E \& Keshavarz M (2017). Climate change and agriculture: Impacts and adaptive responses in Iran. Journal of Integrative Agriculture 17(1): 1-15 https://doi.org/10.1016/s2095-3119(17)61794-5

Lamperti F, Dosi G, Napoletano M, Roventini A \& Sapio A (2017). Faraway, so close: Coupled climate and economic dynamics in an agentbased integrated assessment model. Journal of Ecological Economics 150: 315-339 https://doi.org/10.2139/ssrn.2944328

Lobianco A \& Esposti R (2010). The regional multi-agent simulator (RegMAS): An open-source spatially explicit model to assess the impact of agricultural policies. Journal of Computers and Electronics in Agriculture 72(1): 14-26 https://doi.org/10.1016/j.compag.2010.02.006

Mitter H, Larcher M, Schonhart M, Stottinger M \& Schmid E (2019). Exploring farmers' climate change perceptions and adaptation intentions: Empirical evidence from Austria. Journal of Environmental management 63(6): 804-821 https://doi.org/10.1007/s00267-019-01158-7

Schindler J (2009). A multi-agent system for simulating land-use and land-cover change in the Atankwidi catchment of Upper East Ghana. Unpublished $\mathrm{PhD}$ thesis, Faculty of mathematics and natural sciences, University of Bonn, Germany http://hdl.handle.net/20.500.11811/4160

Seo B, Crown C, Rounsevell M (2018). Evaluation and calibration of an agent based land use model using remotely sensed land cover and primary productivity data. In: proceedings of the IEEE International Geoscience and Remote Sensing Symposium, 22-27 July, Valencia, Spain https://doi.org/10.1109/igarss.2018.8518023

Valbuena D, Verbung P H, Bregt A \& Lightenberg A (2010). An agent-based approach to model land-use change at a regional scale. Journal of Landscape Ecology 25(2): 185-199 https://doi.org/10.1007/s10980-009-9380-6

Wossen T, Berger T, Mekbib G H \& Troost C (2017). Impacts of climate variability and food price volatility on household income and food security of farm households in East and West Africa. Journal of Agricultural systems 163: 7-15 https://doi.org/10.1016/j.agsy.2017.02.006

(C) 2021 by the authors. Licensee Ankara University, Faculty of Agriculture, Ankara, Turkey. This article is an open access article distributed under the terms and conditions of the Creative Commons Attribution (CC BY) license (http://creativecommons.org/licenses/by/4.0/). 